\title{
La doble destrucción de Chaitén. Consideraciones sociales, urbanas y territoriales sobre una catástrofe ${ }^{1}$
}

SONIA REYES HERRERA

> Instituto de Sociología Universidad de Valparaíso, Valparaíso, Chile.sonia.reyes@uv.cl

JUAN CARLOS RODRÍGUEZ TORRENT

> Escuela de Diseño Universidad de Valparaíso, Valparaíso, Chile. juancarlosrodriguez@yahoo.com

FERNANDO MANDUJANO BUSTAMANTE

> Universidad de Playa Ancha, Valparaíso, Chile. fmandujan@yahoo.es

Universidad de Valparaíso

Facultad de Arquitectura

Revista Márgenes

Espacio Arte Sociedad

La doble destrucción de Chaitén. Consideraciones sociales,

urbanas y territoriales sobre una catástrofe

Diciembre 2014 Vol. $11 \mathrm{~N}^{\circ} 15$

Páginas 57 a 68

ISSN elec. 0719-4463

ISSN imp. 0718-4034

Recepción: Junio 2014

Aceptación: Octubre 2014

\section{RESUMEN}

Una erupción volcánica el año 2008, que arrasó y despobló la localidad de Chaitén, no sólo desató cambios dramáticos en la demografía y en las biografías de sus pobladores, sino también propició iniciativas que pusieron a prueba la capacidad de diversas instituciones, incluyendo a la sociedad civil, para gestionar exitosamente la reconstrucción de la normalidad de la vida urbana y comunitaria. Este trabajo se propone describir y analizar esos acontecimientos.

Con la estrategia del estudio de caso y una etnografía multisituada, se recolectó información de terreno y de los medios de prensa, centrada en los discursos que construyeron la narración social del proceso, para presentar el conjunto de variables intervinientes en lo que será históricamente una doble catástrofe y el desencuentro entre la comunidad, la academia y la institucionalidad política.

PALABRAS CLAVE

Chaitén, catástrofe, evacuación, desconfianza, ciudad modelo

\section{The double destrucction of Chaitén. Social, urban and territorial considerations over a disaster ABSTRACT}

A volcano eruption in 2008 devastated and depopulated a small town called Chaitén. The eruption not only provoked dramatic changes in the demography and biography of its inhabitants, but also incentivized initiatives that put to the test the capacity of different institutions, including the civil society to successfully manage the reconstruction of normal urban and community life. This paper aims to describe and analyze those events. Case study strategies and a multi situational ethnography methodology were used in order to collect information in situ and the media, focused on discourses built by the social recounting of the process with the aim to present all the variables involved in what is going to be historically a double disaster and the disagreement between the community, the scholars and the political institutionalism.

KEYWORDS

Chaitén, disaster, evacuation, mistrust, model city

\section{La double destruction de Chaiten. Considerations sociales, urbaines et territoriales à propos d'une catastrophe RÉSUMÉ}

L'éruption volcanique de l'année 2008, qui a ravagé et dépeuplé le village de Chaiten, non seulement a engendré des modifications démographiques et biographique dramatique au sein de sa population, aussi a propulsé des initiatives qui ont mis a preuve la capacité des institutions public, en incluant la société civil, pour réussir la normalité dans la gestion du processus de reconstruction de la vie urbaine et communautaire. Cette recherche propose décrire et analyser ces faits. 
Avec la stratégie d'une étude de cas et d'une ethnographie multi situationnel, nous avons recueilli information sur le champ et dans les médias, centrés dans le discours qui ont construit le récit social du processus, pour présenter l'ensemble de variables impliquées dans ce qui sera connue comme la double catastrophe et le désaccord entre la communauté, l'académie et l'institutionalité politique.

MOTS CLÉS

Chaitén, catastrophe, évacuation, méfiance, ville modèle

\section{INTRODUCCIÓN}

Si bien Chile tiene una de las economías reconocidas como las más desarrolladas de Latinoamérica y un nivel de ingresos altos de su población, el país tiene un flanco con el cual se enfrenta cada cierto tiempo: los desastres naturales. Chile es una tierra de sismos y tiene la más importante cadena de volcanes a nivel mundial, de los cuales una centena se encuentra activos.

Por definición, un desastre se da dentro de las ocurrencias ordinarias o extraordinarias de un fenómeno natural y refiere a pérdidas humanas y materiales ocasionadas por fenómenos naturales o intervenciones humanas. Además, es localizable en el tiempo y el espacio, afecta a una comunidad que ve alterada su funcionamiento, pérdidas en vidas, efectos sanitarios y materiales en los bienes y servicios, impidiendo el normal desarrollo de las actividades esenciales (Wilches-Chaux, 1993). Los fenómenos naturales pueden ser regulares como la lluvia o inesperados como un sismo, un tsunami o la erupción de un volcán. Se estima que en Chile, en las últimas dos décadas, unas 350.000 personas han debido ser asistidas con planes de emergencia y reconstrucción producto de terremotos, maremotos, incendios, erupciones, nevadas e inundaciones, debiendo el Estado desembolsar importantes recursos anuales para paliar los diversos efectos.

En general, para estos casos, la literatura establece diferencias y afirma que: el manejo de los desastres en los países industrializados continúa siendo un problema fundamentalmente logístico: rapidez en la respuesta y eficiente localización de elementos apropiados de socorro en los lugares y momentos necesarios. En el Tercer Mundo, en cambio, si bien la logística constituye un factor esencial para la atención de las emergencias, el problema es más de fondo. Durante los desastres se evidencian y agudizan las amenazas contra la vida, los bienes y las oportunidades de los miembros de las comunidades afectadas; de manera activa o potencial, esas amenazas están siempre presentes en el medio. Muchas veces, incluso, la atención y solidaridad pública que despierta el desastre, constituyen, por decir lo menos, una ruptura temporal de esa "rutina de amenaza" que es "lo normal" en la comunidad (WilchesChaux, 1993:12). Por ello, suele ocurrir-como observaremos en este estudio de caso- un proceso de re-narración que va modificando los recuerdos, los traumas, que cambian la definición de las situaciones, y por lo tanto las consecuencias de las catástrofes.

Lo señalado, constituye la reflexión de este artículo. Trata sobre la erupción del Volcán Chaitén que afectó a la ciudad homónima en la provincia de Palena, en el mes de mayo de 2008. Refiere a sus efectos sociales, urbanos, territoriales y su recomposición urbana a partir de un prematuro olvido, en el mismo lugar donde ocurrieron los hechos.

Metodológicamente, hemos utilizado el método del estudio de caso, que tal como lo señala Yin (2003) se destaca por su utilidad -en vez de la encuesta, el experimento u otro-. La información contenida está asociada a registros de campo como parte de un trabajo etnográfico del tipo multisituado, es decir, con registros en distintos centros de atención y pesquisa de información primaria, y apoyado por información secundaria recogida previa y posteriormente al suceso que describiremos. Cuando se necesita hacer visibles procesos (how, why?), actuales o presentes y no se requiere manipular alguna variable o situación. El procedimiento se adecúa a la profundidad que requiere un trabajo en la perspectiva cualitativa hermenéutica, ya que está dotado de flexibilidad para procesos y relaciones frecuentemente imprevistas, emergentes, tanto durante el trabajo de terreno, como en el análisis de los datos (Yin, 2003; Stake, 1978).

La información contenida está asociada a registros de campo como parte de un trabajo etnográfico del tipo multisituado, es decir, con registros en distintos centros de atención y pesquisa de información primaria, y apoyado por información secundaria recogida previa y posteriormente al suceso que describiremos. Paralelamente se elaboró un archivo de prensa, con el abundante material publicado desde el año 2008, a ello se sumó artículos e informes originados con la catástrofe y su gestión, documentos y bases de datos públicos que se unieron a las transcripciones de las entrevistas a informantes claves, y material fotográfico recabado. Para la validación se cruzó la diversidad de fuentes, pero en especial, se procuró la cristalización de la información que da cuenta de la complejidad del objeto de estudio, través del análisis iterativo y cíclico (Fetterman, 2010).

\section{CHAITÉN: LA ZONA CERO}

En la madrugada del día 2 de mayo de 2008, el volcán Chaitén, ubicado en la provincia de Palena en la Patagonia chilena, después de miles de años inactivo (Lara, 2009:126), inició la actividad eruptiva más grande de su tipo conocida desde el año 1912, en Alaska (Carn et alters, 2009:205). Su impresionante columna de gases y cenizas alcanzó más de 25 kilómetros de altura (NASA, 2008), extendiéndose a la costa atlántica y cubriendo con cenizas parques nacionales y localidades pobladas de Chile y Argentina, incluyendo algunos días, la Capital Federal Buenos Aires. De todas ellas, la más afectada fue Chaitén, ubicada a sus pies, que llamaremos Zona Cero, distante a unos 10 kilómetros, y cuyos 4.625 habitantes urbanos fueron evacuados.

La Zona Cero constituye el epicentro, es decir, la zona de mayor afectación o concentración de daño producto de una catástrofe derivada de un accidente natural o premeditado de importante magnitud (Oxford Dictionary, 2014). Es tal su impacto, que modifica todo aquello que se encuentra dotado de sentido, es decir, lo que en antropología se llama lugar; lo que expresa la articulación entre la identidad, las relaciones y la historia (Augé, 1983); afecta las manifestaciones icónicas, la configuración de sentidos y la relación con los volúmenes de arquitectura cuando estamos en el espacio urbano como ocurrió con Chaitén. 


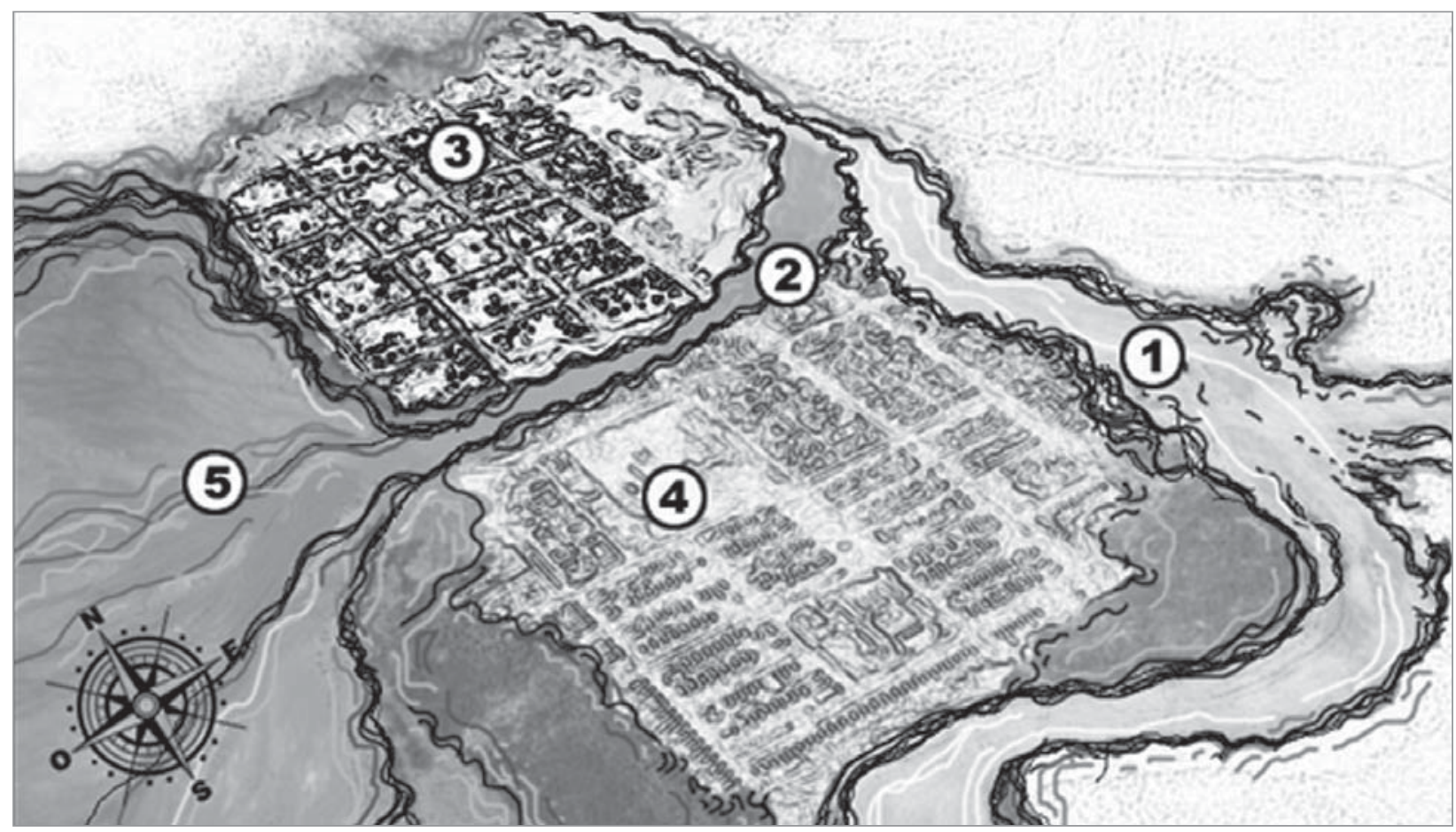

La emergencia derivada de la erupción fue tan inesperada y violenta, que no hubo márgenes de tiempo, burocracia y de evaluación pausada para el inicio del traslado de sus habitantes. La orden fue perentoria: evacuar. Como pocas veces se ha visto, para una zona definida como extrema, aislada y de escaso agenciamiento del Estado, observamos un despliegue inusitado de recursos materiales y humanos que se pusieron a disposición para salvar a la población local, de poblados y comunas aledañas. Hombres, mujeres, niños y niñas son llevados de manera dispersa principalmente a la capital regional Puerto Montt; otros, a Castro y Quellón, en la Isla de Chiloé. Usando sus propios medios de trasporte, algunos se dirigieron hacia Coyhaique, unos 400 kilómetros hacia el sur, o a localidades del interior como Palena y Futaleufú en la frontera con Argentina.

A los 10 días de esa evacuación, con las intensas lluvias de otoño y la acumulación de cenizas y sedimentos, se desborda el cauce natural del río Blanco (Figura 1), arrasando con gran parte de las casas, calles e infraestructuras; en la zona costera, producto de la acumulación de sedimentos desaparece la caleta de pescadores y queda inhabilitado el muelle de transbordadores, infraestructura clave para la conectividad terrestre y marítima entre Chile y "Chile interior" que representa la Patagonia. Con ello, el mar se recoge algunos cientos de metros.

Desde el punto de vista humano, lo vivido corresponde al descentramiento ritual de la vida cotidiana, porque se pone fin a un pacto entre el hombre y su mundo (su memoria), el hombre y la ciudad, el hombre y la naturaleza (Reyes et al. 2014:240). Es una violencia que atenta contra la biografía, que obliga a revisar los contenidos de la propia vida de aproximadamente 1.900 familias. En la desaparición de gran parte del pueblo hay un yo ausente y exiliado, un vacío que dejan los referentes sociales para disolverse en lugares inconexos. El conjunto de ruinas urbanas son las heridas que expresan los cambios de la vecindad, la estructura ocupacional, la pérdida de cierta intimidad, su ritualidad y las lealtades que se construyeron en el tiempo. Por eso, la ruina de Chaitén connota más allá de su denotación, pues detrás de ella hay una emoción, un sentido muy subjetivo que arrastran sus habitantes. Es desamparo y abandono de una biografía; es un quiebre, es siempre un trauma.
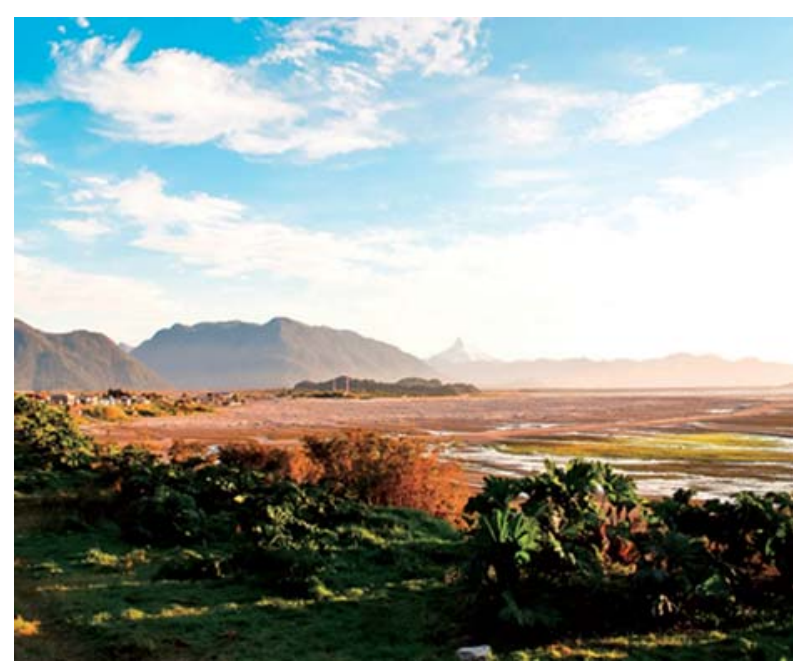

$>$ Figura 1: Croquis de la planta de Chaitén. Se identifica el curso del río Blanco (1) y su nuevo curso que fractura la ciudad (2); el sector norte (3), donde las zonas más cerca del mar fueron las menos afectadas; el sector sur (4), resultando totalmente destruidas unas 400 viviendas; y, la bahía y su zona intermareal (5) cubierta por toneladas de piedras y cenizas. Croquis de Manuel Astudillo.

Fotografia 1: Zona intermareal cubierta por sedimentos y piedras producto de la erupción. Fotografía de los autores. 

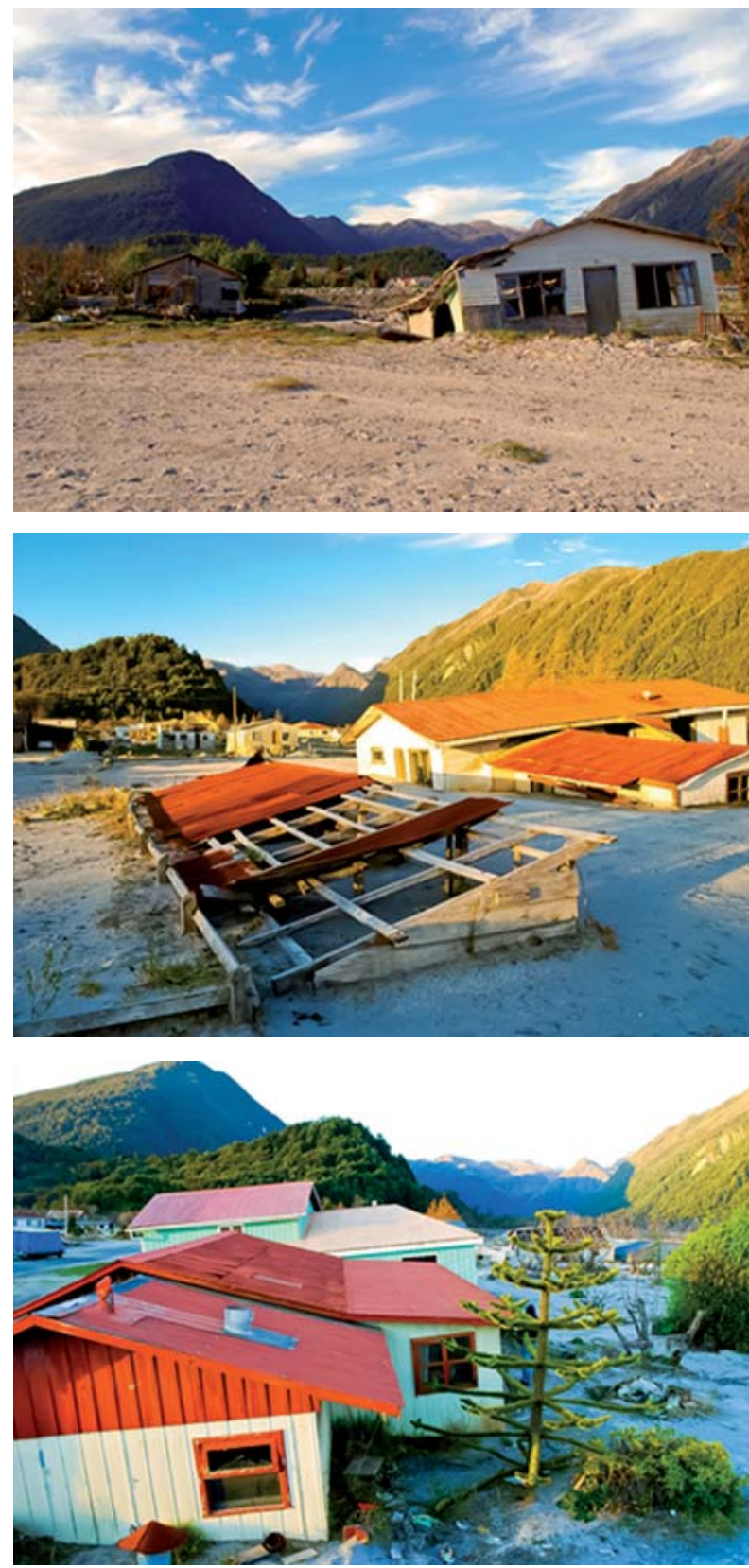

$>$ Fotografía 2. Zona norte de Chaitén.

$>$ Fotografía 3. Destrucción zona sur de Chaitén.

$>$ Fotografía 4. Destrucción de la zona sur de Chaitén.
Con la imagen de la destrucción, se produce un encadenamiento superlativo de imágenes que catapultan a Chaitén y su población por el mundo. El poblado es recorrido por la prensa una y mil veces en su devastación con juguetes abandonados, enseres domésticos, ropa, muebles, bicicletas, libros, fotografías, documentos personales, dejando de ser de sus habitantes hasta convertirse en un fenómeno esencialmente mediático y reiterativo. Estuvo en los titulares de los noticiarios y en las portadas de los periódicos del mundo, tomando fuerza las impresionantes imágenes y noticias divulgadas por corresponsales de cadenas radiales y televisivas. En solo 10 días, la fumarola fue portada mundial; mientras, las casas se hundían y desaparecían hasta quedar sepultadas con las miles de toneladas de cenizas sobre sus techos (Fotografías 2, 3 y 4) y los desplazados miraban sus propios rostros desencajados, entrevistados en su dolor en distintos lugares y eran observados por el mundo.

De este modo, lo natural, lo social y lo mediático se amalgamaron para desencadenar un complejo proceso decisiones, hechos y también amenazas, que expresan la separación obligada de la tierra en que se vive, es decir, un éxodo y emigración forzada, cuyos impactos afectan y afectarán durante muchos años la vida de los desplazados y la zona, ya que se modifica el volumen y composición de la población. Las personas evacuadas se volvieron más vulnerables, dependientes y frágiles en la medida perdían cada elemento y conjunto de elementos que eran propios de su cotidianeidad, ya que nada estaba dentro de sus posibilidades de control.

Al mismo tiempo que se extendía la fumarola y se alargaba la estancia de corresponsales, la sucesión de decisiones y hechos de las autoridades proporcionaban una oportunidad para hacer visibles algunos rasgos cruciales de la vida y definición territorial de la Patagonia y la Provincia de Palena como la demografía, la conectividad, la precariedad de los embarcaderos y aeródromos, de la cual era parte Chaitén (Véase Figura 2)

Si se aprecia el mapa, Chaitén es un lugar estratégico para dar continuidad a Chile. Es un punto nodal para la conectividad vial de la provincia de Palena y para la conectividad interior de Chile, ya que camiones con alimentos y combustibles, vehículos particulares y servicios de transporte deben pasar tras combinaciones terrestres y marinas necesariamente por el poblado para dirigirse al norte $o$ avanzar hacia el sur del país. A esta fórmula se le llama bi-modal, en cuanto la falta de continuidad terrestre es cubierta por los transbordadores. Esto, no resta dificultades, ya que la conectividad es frágil e insegura y no es siempre regular, debido a que factores climáticos como la lluvia, el viento y el frío son extremadamente adversos para transitar por caminos ripiados, estando la navegación en lanchas y barcazas supeditadas a estos factores. De no usar la ruta bi-modal, el camino obligado para ir al Chile patagónico, interior y costero, es por las carreteras argentinas.

Entonces, no fue menor lo ocurrido en Chaitén desde el punto de vista de la relación entre desastre y también la continuidad territorial. En paralelo, debemos destacar que, por una parte, lo importante es que las narraciones de científicos y la prensa van decantando un discurso y definiendo día a día los acontecimientos que terminan por establecer una territorialidad con menos moradores en esta localidad Patagónica y articuladora territorialmente entre norte y sur; por otra, se afianza la idea del "desplazado ambiental": los habitantes de Chaitén que son obligados a trasladarse donde la autoridad decida, puedan o sean recibidos con tal de ofrecer 
seguridad inmediata, arrastran con ello el desarraigo, generan condiciones de aculturación, desintegración familiar y social de las personas cercanas.

\section{LA ERUPCIÓN DEL VOLCÁN CHAITÉN: LA SECUENCIA DE LOS ACONTECIMIENTOS}

La etapa de emergencia fue la evacuación de los habitantes, que a un mes de iniciada la erupción estaba concluida. En el pueblo no quedó nadie y puede considerarse ejemplar desde el punto de vista de la eficiencia de las autoridades políticas y la participación de las Fuerzas Armadas. A partir de ese momento comienza el azaroso camino del restablecimiento de la normalidad, sin que a nadie faltara techo y comida.

Para las autoridades no será fácil resolver el caso de los casi 5 mil desplazados, porque los dineros para la reconstrucción siempre son remesas extras y no fueron comprometidos en la partida presupuestaria 2009 de la administración Bachelet. Además, por la cuantía de los montos no podrían ser incorporados a un nuevo período presidencial entrante. En este sentido, se debían conciliar tres cuestiones: a. lo que quería la gente: volver bajo ciertas condiciones o irse definitivamente, b. los recursos que podían ser asignados, y c. la posición estratégica para la conectividad al momento de tomar una decisión sobre el futuro emplazamiento.

En este proceso, lo más importante fue que la Delegada de la Presidencia Paula Narváez, fue capaz de explicitar que consultada la opinión de los involucrados en distintos "cabildos ciudadanos" realizados en distintas localidades donde se albergaban los afectados sobre las características de un nuevo poblado, sería "otro gobierno" a quién corresponda tomar la decisión de cuánto invertir y cómo se ejecutaría el proyecto consensuado. Sin embargo, la espera para muchos ya era eterna porque los tiempos del sufriente, de la academia y de los políticos tenían diferentes urgencias. Por ello, no faltaron banderas argentinas como signo de protesta; y, lo más grave, en una reunión colectiva un chaitenino vestido como gaucho y con acento trasandino señaló: si su gobierno no quiere poner plata acá, nosotros se la pasamos².

Con ello, se produjo el quiebre con la delegación presidencial, y algunos de los chaiteninos que tenían más influencia y recursos, iniciaron su camino propio para la reconstrucción del sector norte (Figura 1, zona 3), el menos dañado, transformándose en los emprendedores y rebeldes frente a lo que consideraban la inacción del Estado.

De este modo, el período pos emergencia tuvo varios hitos.

Primero, la declaración de los expertos respecto de la inhabitabilidad del lugar. Las impresionantes imágenes de la erupción, desde la zona y satelitales de la National Aeronautics and Space Administration (NASA) y United States Geological Survey (USGS), recorrieron la prensa internacional, agregando notas en directo de la evacuación de las personas, el rescate de las mascotas, las condiciones de los refugiados y la destrucción de la ciudad. Estas difundieron la imagen del pueblo y la zona como un verdadero holocausto, lo que presionó a las autoridades para implementar permanentemente más ayuda y apoyo para los evacuados, confirmando la idea de la existencia de un Chile lejano y desconocido.

Esto fue avalado por el primer informe técnico del Servicio Nacional de Geología y Minería (SERNAGEOMIN) (3 mayo 2008) que decreta Alerta Roja, identifica al pequeño volcán Chaitén y no al Michin-
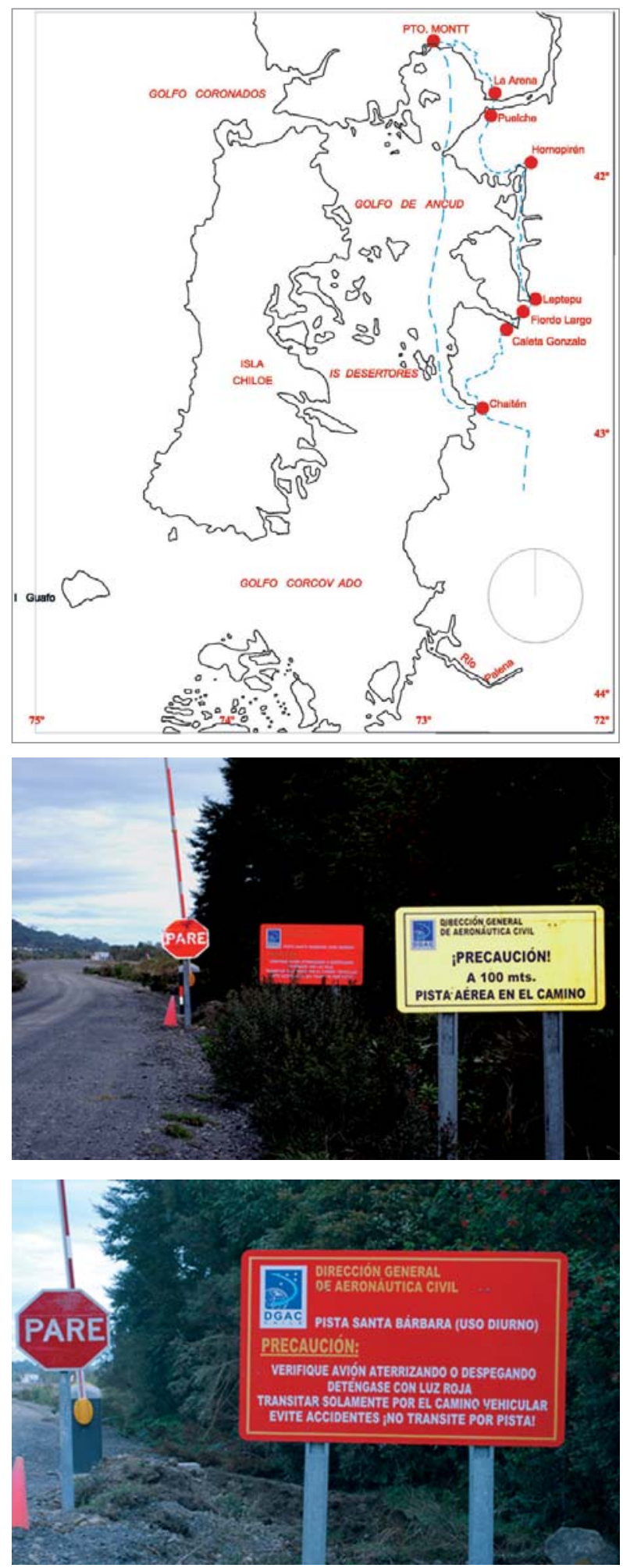

$>$ Figura 2. Mapa conectividad Chaitén. Elaboración de los autores.

$>$ Fotografía 5. Pista aérea de Chaitén, la que es parte de la ruta G o Carretera Austral.

$>$ Fotografía 6. Anuncio que alerta sobre la posibilidad de un aterrizaje 0 despegue de un avión sobre la carretera. 
mahuida, más grande y a pocos kilómetros, como causante de la erupción. Se recomienda la evacuación de toda la población, y agrega: la evolución de la erupción es de difícil pronóstico, pudiendo continuar por días, semanas o meses (o años). Los adjetivos que emplean los expertos para definir la situación de la ciudad son inequívocos: destruida, devastada y arrasada, por lo que sería imposible su reconstrucción.

Efectivamente ocurre el peor escenario: La actividad del volcán se mantuvo durante el primer año y en febrero del año siguiente (el 2009) colapsa la estructura central del cráter y se advierte: ninguna persona debe permanecer en la ciudad de Chaitén y se mantiene la Alerta Roja.

Segundo, la etapa de preparación para el regreso, estuvo definida por dos actividades que debieron complementarse pero que en la práctica se hicieron mutuamente excluyentes: la normalización de la vida de las familias y la re-localización y diseño de la Nueva Chaitén.

En el mes de octubre, a casi seis meses del suceso, el gobierno contrata la realización de un estudio a la Pontificia Universidad Católica de Chile para reconstruir o relocalizar Chaitén, el que deriva prontamente al estudio de la re-localización. Este tuvo como opción velar por la seguridad, ya que Chaitén no está libre de peligro y vive dentro de límites vulnerables. Así, recién al tercer año, en junio de 2010, SERNAGEOMIN baja la calificación a Alerta Amarilla, pero ratifica otras opiniones de expertos: Dada la gran dimensión del domo, continúa latente el peligro de colapsos, eventuales explosiones y generación de flujos de bloques y ceniza, los cuales podrían afectar los valles adyacentes al volcán Chaitén (El Mercurio, 2 junio 2010). En junio de 2012, la autoridad regional del Ministerio de Vivienda y Urbanismo afirma: “...Chaitén completo es un territorio vulnerable frente a peligros naturales, por lo que su ocupación siempre conllevará un riesgo para las personas que lo habiten o realicen actividades en él y también se arriesga la pérdida o el serio deterioro de la infraestructura localizada ahí" (Macaya, 2012:5). De este modo, se reconoce la persistencia del riesgo, es decir, la relación entre la amenaza (o su posibilidad) y la vulnerabilidad.

La importancia de estas afirmaciones es crucial, pues constituyeron el marco dentro del cual se van a mover siempre las autoridades locales y nacionales para gestionar la etapa de solución de la catástrofe. Ellas hacen suyo el veredicto de expertos vulcanólogos entrevistados permanentemente en la prensa, lo que va a operar como una profecía y una amarra para su accionar.

Tercero, a unos meses de ocurrido el suceso, para sacar dividendos a la expectativa turística que ha generado la cobertura mediática, algunos chaiteninos que desestimaron advertencias de las autoridades ("rebeldes") y que permanecieron clandestinamente, organizaron paquetes de visita al cráter (Radio Cooperativa, 20 enero 2010); y, unos tesistas de la Pontificia Universidad Católica de Chile proponen transformar Chaitén en un pueblo fantasma al estilo de Humberstone (antigua oficina salitrera), abriéndose las posibilidades de hacer camping y recorrer el lugar a través de senderos en las cenizas (Plataforma Urbana, 26 febrero 2009).

Esto refuerza cada vez más que la exposición mediática y económica de la tragedia, no sólo fue parte de las perturbaciones que tuvieron que soportar los habitantes de Chaitén evacuados y refugiados en tres regiones chilenas (Aysén, Los Lagos y Los Ríos) y en algunas ciudades argentinas (Bariloche, Trevelin y Esquel), sino que también fue una de las tantas formas en que vivieron la expe- riencia. En noticieros y reportajes especiales vieron el nuevo curso y volumen del río, sus casas destruidas por el peso de las cenizas, sus mascotas abandonadas y la vida en los refugios de ellos y de otros chaiteninos (Marchant 2010). Con ello, la apreciación de una ciudad destruida fue más aguda y también que su reconstrucción se veía lejana y no dependía de ellos mismos, sino que se requería de la necesidad de una intervención estatal mayor y de tiempos que no podían controlar.

Cuarto: la apropiación de Chaitén por algunos autodenominados rebeldes, ubicados en localidades relativamente cercanas y que tuvieron mayor facilidad para regresar a mirar, recuperar, o reinstalarse, son los vecinos que insisten -muy tempranamente- en la reconstrucción de Chaitén en la zona norte y que van a resultar claves para decidir su destino final. Estos, comienzan a apropiarse del pueblo y rehabilitarlo "a pulso" y "sin ayuda del Estado", trayendo combustible de manera clandestina desde Argentina.

En febrero de 2009, a menos de un año del inicio de la crisis, el vecino Riquelme declaraba una verdad fundamental: La gente que está en Chaitén es la que tenía algo y la que generaba movimiento en el pueblo (Burgos, 2009). De este modo, quienes defendieron la opción "Chaitén en Chaitén", en su mayoría son dueños de negocios como almacenes, supermercados, restaurantes, cocinerías, cabañas y albergues para turistas. Muchos son nietos de colonos, tienen inversiones o un espacio de negocios ganado por años, difícil de replicar en otras partes.

Son ellos los que a pocos meses de la evacuación total, regresan y pese a las prohibiciones, hacen funcionar el pueblo: instalan bombas de agua, generadores eléctricos e importan clandestinamente combustible desde las ciudades argentinas de Esquel o Trevelin. Además, protagonizan diversas protestas y boicotean los rudimentos de un nuevo emplazamiento para Chaitén, donde algunos enarbolan banderas Argentinas y aparecen por primera vez en la zona las bombas lacrimógenas de la policía antidisturbios.

Quinto: Durante todo este tiempo, el gobierno instaló equipos de gestión directa y el mayor financiamiento por persona destinado por el Estado a paliar una catástrofe en Chile hasta esa fecha ${ }^{3}$, con alrededor de 80 profesionales y autoridades dedicadas al apoyo de la población afectada en las localidades de refugio. La asistencia económica del Estado se tradujo para la mayoría de las familias en ingresos impensados (La Tercera, 14 mayo 2008), en una comuna que tradicionalmente tuvo ingresos medios inferiores a la región y al país. Entre éstos:

1. Cada grupo familiar recibió $\$ 500.000$ mensuales;

2. Si existen hijos estudiando, hasta 24 años, se suman $\$ 20.000$ más;

3. Si un hijo laboraba al momento de la erupción y vivía en el mismo techo de sus padres, recibía $\$ 300.000$ pesos;

4. Se incorpora un subsidio habitacional de 670 UF, equivalente a la fecha a unos 14 millones de pesos para la compra de una propiedad en el lugar que estimen conveniente y en cualquier lugar de Chile;

5. El Ministerio de Bienes Nacionales expropiará las casas y pagará un valor comercial equivalente al 30 de abril de 2008;

6. Se mantuvo por más de 12 meses el apoyo de asistentes sociales, sicólogos y de todos los servicios públicos. 


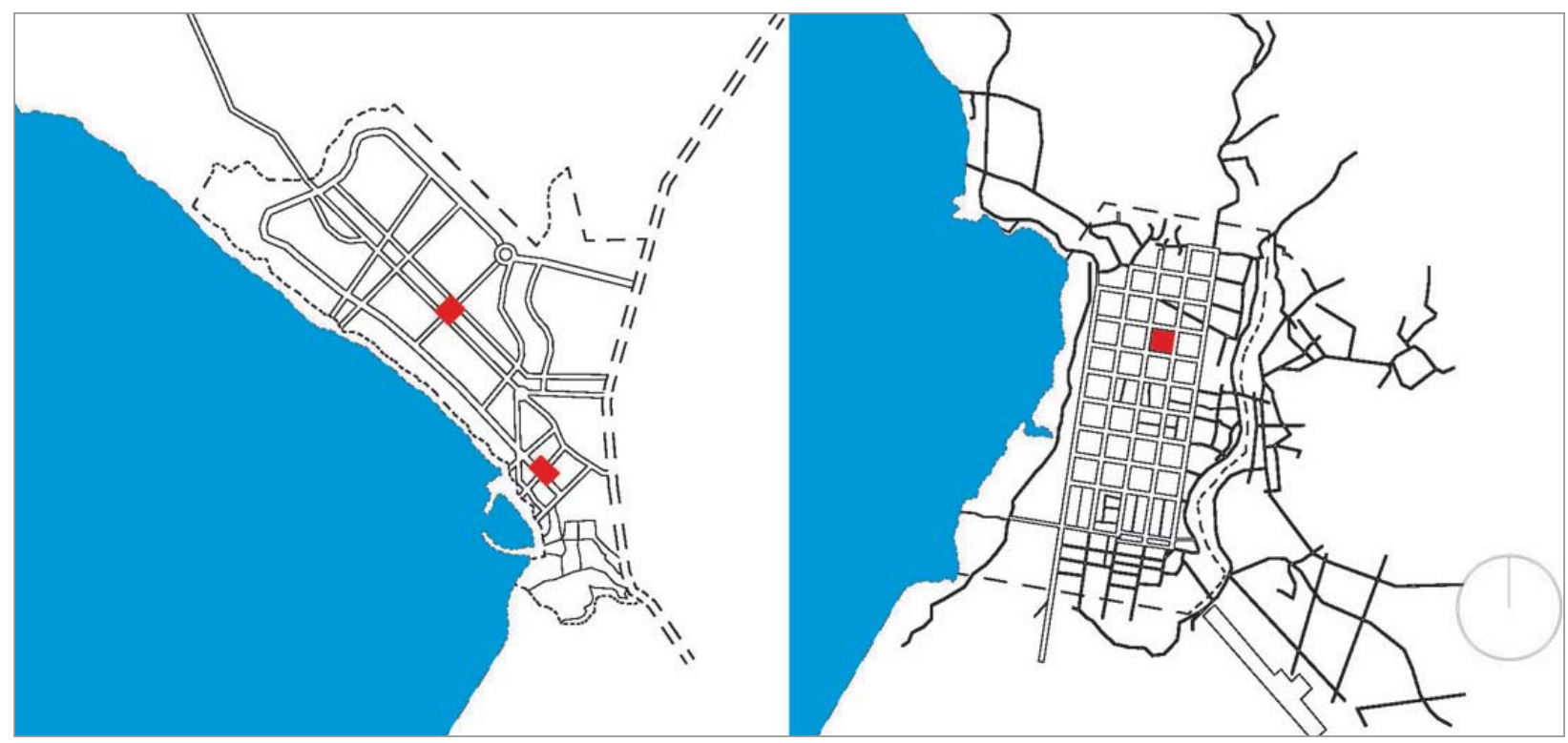

Además de disponer de esos recursos materiales y profesionales, se enfatizó en el asesoramiento científico de la gestión, consultando y contratando servicios de expertos en las diversas disciplinas vinculadas al problema de las catástrofes, incluyendo instituciones chilenas (SERNAGEOMIN, OVDAS, Universidades) y extranjeras (ARUP, VHP-USGS ${ }^{4}$, NASA). Lo más importante en este ámbito es el estudio encargado a la PUC, en equipo con la Universidad Austral y la Consultora ARUP, sobre las posibilidades de relocalización y el parecer de la gente dispersa.

Mirada a la distancia, entre las medidas gubernamentales hubo dos que tuvieron una alta incidencia en la decisión de volver o no a Chaitén: a. la Ley $N^{\circ} 20.385$, del 7 de octubre de 2009, que autorizó al Estado a comprar las propiedades en el pueblo al valor que tenían antes de la catástrofe, b. que el Ministerio de Obras Públicas (MINVU) creó un alto subsidio especial para la vivienda.

Sin embargo, a fines de mayo de 2009, a un año de la evacuación total, según la Cuenta Pública de la Delegada Presidencial (2 mayo de 2009) se presentó como un logro la entrega exitosa de 1.878 subsidios para vivienda, y que al 26 de abril de 2010, plazo final establecido por el instrumento legal, el $83 \%$ de los beneficiarios con la Ley que permite vender sus propiedades al fisco, había aceptado esta opción.

Sexto: El gobierno de la Presidenta Bachelet recibe durante el primer semestre del 2009 los Informes contratados, y en seguida, con los equipos profesionales del MINVU elabora el Plan Maestro para la construcción de la Nueva Chaitén. Este trabajo culmina con una propuesta de relocalización en Santa Bárbara, caserío ubicado 10 kilómetros al norte. El resultado se expresa en un proyecto de ciudad modelo, en sintonía con la identidad de futuro de la Patagonia y acreditada como ciudad ecológica (PUC, 2009) y de conformidad a cómo también lo querían los chaitenínos dispersos, quienes habían sido convocados a participar de focus group y entrevistas.

Las características de la propuesta, incluyó la participación del mayor número de ciudadanos dispersos y dispuestos a escuchar y opinar. Su importancia tiene tres componentes centrales:

1. Es desarrollado por una instancia académica como contraparte;

$>$ Figura 3. Plano de Chaitén pre erupción y nueva propuesta. Croquis de Manuel Astudillo. 
2. Genera una metodología inclusiva y participativa respecto de los habitantes dispersos;

3. Realiza una evaluación de la amenaza para el ordenamiento territorial y la planeación. El nuevo emplazamiento ubicado en Santa Bárbara, 10 kilómetros más al norte, es el resultado de un riguroso proceso de selección de un sitio que debiese mantener las ventajas estratégicas de Chaitén, que como declaraba el informe PUC-U. Austral (2009), debía ser paso obligado de la ruta G7, contar con sectores adecuados para puertos y aeródromos. Además, protegerse del riesgo eventual de tres volcanes vecinos: el Chaitén (1.122 msnm), el Michimahuida (2.450 msnm) y el Corcovado (2.300 msnm). Los estudios para la relocalización eligieron una superficie de 100 hectáreas notoriamente más grande que las 63,33 hectáreas del poblado arrasado, las que se consideraron aptas para una capacidad de carga de unos 5 mil habitantes, número superior al de la ocupación pre-erupción.

Las ideas principales tuvieron que ver con:

1. Diseñar una imagen urbana para Chaitén, la puerta de entrada para la Patagonia;

2. Una ciudad que debía albergar unas 5 mil personas;

3. Convertirla en un centro turístico internacional por la cercanía a los volcanes, Parque Pumalín, lagos y ríos;

4. Debía ser sustentable económica, ambiental y socialmente;

5. Debía tener espacios públicos y recreativos, infraestructura escolar y de salud, conjuntos residenciales, calles y senderos posibles;

6. Debiese tener una costanera, con un mercado para la venta de alimentos, lanas, productos del mar y con buenas calles.

En abril del año 2009, sin haber asumido aún los beneficiarios esta propuesta, el Intendente regional anuncia que se descarta la propuesta PUC, por el costo de los predios privados que contempla, y el MINVU con sus propios equipos profesionales, sorpresivamente, elabora un nuevo proyecto para la Nueva Chaitén (La Tercera 16 abril 2009), asentado en la misma localidad de Santa Bárbara, pero, sobre suelos fiscales.

A los pocos días de asumido el gobierno del Presidente Piñera, y aún con las réplicas del terremoto y tsunami del 27/F, en marzo de 2010, el MINVU entrega el Plan Maestro Ciudad Chaitén. El informe refuerza cuestiones anteriores y propone una ciudad con una fuerte identidad paisajística y cultural, que incorpore criterios de sustentabilidad ambiental, social y económica, que garantice una alta calidad de vida para sus habitantes, y que se consolide como la puerta de acceso a la Carretera Austral (División de Desarrollo Urbano - MINVU 2010).

Lo importante aquí es el problema de los tiempos y la oportunidad de las decisiones. La adaptación en otras localidades mejor dotadas de servicios, con más opciones de estudio para los hijos, de trabajo, diversión, conocimiento de personas, que lo que ofrecía el pequeño pueblo y la provincia antes de la catástrofe, se vio reforzada por la falta de vivienda, dificultando la urgencia del retorno y provocando un importante proceso aculturativo. Esto fue especialmente vivido por aquellos evacuados por mar y que encontraron refugio en centros urbanos más grandes y lejanos.
En mayo, el nuevo gobierno confirma la construcción en Santa Bárbara (Diario La Nación, 27 mayo 2010), y, transcurrido casi un año después, en abril de 2011, cambia de decisión y anuncia la reconstrucción de Chaitén en el sector norte del mismo pueblo, en lo que denomina "Plan Solución Chaitén”, exactamente el lugar sugerido por los denominados rebeldes hace más de tres años. Con ello, ocurren al menos 4 cuestiones: 1 . se abandonan las propuestas de la PUC y del MINVU, lo que refuerza el descrédito de las autoridades nacionales; 2 . se impone la propuesta de los chaiteninos “rebeldes", es decir, la reconstrucción en el mismo emplazamiento; 3. se define la escala demográfica en función de las viviendas disponibles y recuperables; y 4 . se refuerza la idea de una ausencia de política territorial para la Patagonia, lo que mantiene la idea de la existencia de un Chile interior.

Séptimo: Todo lo que emprendió el gobierno de M. Bachelet para reconstruir la normalidad, se hizo aceptando la declaración de inhabitabilidad del pueblo devastado. Las decisiones corroboran no permitir el repoblamiento. Al entregarles un poder comprador para adquirir otra vivienda, sumado a un subsidio adicional para el mismo efecto, facilitó la compra de una nueva, para que cada familia se relocalizara de acuerdo a su propia elección, y así no perpetuar indefinidamente el estatus de desplazados, situación que habría sido insostenible para las personas. Por cierto, la recuperación de la normalidad en la vida de las víctimas, es en todos los casos de gestión de catástrofes una prioridad, y en éste, se administraron soluciones para que cada familia pudiese construir por sí misma esa normalidad en un nuevo lugar.

De este modo, cada esfuerzo que se hizo para ayudar a los damnificados a re-hacer sus vidas, hacía menos relevantes para esos cientos de familias el o los proyectos de una nueva ciudad con estándares como "las ciudades argentinas". Entonces, la venta de propiedades de las familias al Estado fue una decisión radical y sin vuelta atrás; y, con ello, ocurren tres fenómenos: a. el extrañamiento, dejaba de ser una espera indefinida para un regreso incierto, y se convertía en el rito de pasaje para un nuevo comienzo, lejos del pueblo destruido y definido como inhabitable; b. el pueblo, curiosamente, en el país más neoliberal de América latina se convertía en un territorio fiscal; y c. se terminaba por destruir todo lo que alguna vez había constituido una comunidad.

Octavo: En 2011 se configura la instalación de unas 160 familias que se toman las casas de la "zona prohibida" o más destruida (Figura 1. zona 4), en el sur del pueblo. Y recién, en febrero de 2013, el Ministerio de Bienes Nacionales puso a la venta 112 inmuebles fiscales, entregándoles la primera opción de compra a sus anteriores propietarios. También ha arrendado alrededor de 70 propiedades a particulares y entregado 49 concesiones y destinaciones para el funcionamiento de diversos servicios públicos, gran parte de ellos que regresan como la Municipalidad, Registro Civil, Ministerio de Bienes Nacionales, Gobernación, Ministerio de Educación, Ministerio Público, Aduana, CONAF, Servicio de Salud, SAG, INDAP e INP.

Noveno: La gestión de la catástrofe de Chaitén contó con el acierto de poner a disposición de la comunidad académica la tarea de contribuir a su estudio y explorar las soluciones posibles. El liderazgo lo impuso el convenio del gobierno con la Pontificia Universidad Católica de Chile (octubre 2008) la cual, en un consorcio con la Universidad Austral, ARUP (una consultora internacional) y el Observatorio de Ciudades PUC, realizó un trabajo que fija un hito en 
la forma de estudiar procesos urbano-territoriales en escenarios de riesgo ambiental en Chile (Observatorio de Ciudades PUC, 2009).

Pese al gran esfuerzo realizado, primero por las universidades y luego los profesionales de la División de Desarrollo Urbano del MINVU, el proyecto de relocalización en Santa Bárbara no prosperó. Todo indica que no logró algún nivel de arraigo, ni despertó confianzas en las expectativas de los habitantes. Ni en los que vivieron -al menos los primeros meses del extrañamiento o refugio-con la esperanza de volver, ni en "los rebeldes" que se negaron a abandonar el pueblo. También, la estimación de un costo de unos US\$ 350 millones, parecía una cifra exorbitante para el Estado, aun cuando fuera para una ciudad modelo y que fijara estándares patagónicos.

El indicador más claro de ello es la absoluta ausencia de alguna manifestación de protesta o reclamo por el descarte definitivo de Nueva Chaitén. Bernardo Riquelme, entrevistado en enero de 2014, la recuerda así: Aquí hubo un invento de parte de alguien que quiso ganarse unas lucas, de una universidad, en donde inventó un estudio a partir de lo que dijo un chaitenino... Eso lo tomó una Universidad... que cobró no sé, 180 millones por hacer un estudio donde se iba a hacer una ciudad, que al final no pasó más que el estudio.

Entre los factores que pueden contribuir a explicar este resultado, Macaya (2012) menciona dos: la presión de los rebeldes y el costo de construir y habilitar la ciudad modelo Nueva Chaitén en Santa Bárbara. A ellos podemos agregar dos factores más: el cambio de prioridades del gobierno entrante, y un efecto disfuncional o paradójico del programa de apoyo a las familias que se tradujo en ayuda para adaptarse lejos, porque el estatus de refugiado indefinido era insostenible. De este modo el vivir separados luego de la evacuación, de manera dispersa entre vecinos y familiares, contribuyó a cortar lazos sociales, afectivos y territoriales. Esto último, constituiría el gran costo social o segunda catástrofe: la ruptura del tejido social. Señala en nuestros registros una joven avecindada en Futaleufú: mis padres se quedaron viviendo en Puerto Montt porque alli hay hospital y mis hermanos mayores se quedaron viviendo en Castro, en la isla de Chiloé, yo me quedé aquí porque como no tengo estudios no tengo posibilidades en las grandes ciudades ${ }^{5}$.

Décimo: La acción de los rebeldes se consolidó como un discurso que terminó por imponerse. A diferencia de los diagnósticos de los expertos, que eran considerados sólo declaraciones, esos vecinos, insistiendo en vivir en el lugar y defendiendo su derecho a hacerlo, terminaron por legitimar, con su propio ejemplo, su diagnóstico de "Chaitén habitable". Su opción tenía otros atributos que los técnicos, burócratas y académicos desconocían, que quizás resultaron más concordantes con el imaginario de la gente de la Patagonia: no rendirse ante la adversidad, no abandonar ni traicionar el lugar y la casa que los vio formar su familia, vencer a la naturaleza como lo hicieron siempre los colonos.

La imposición de este criterio de fuerza, no técnico, por parte de quienes tenían inversiones, termina siendo funcional a algo que también realmente constituía una dificultad política para las autoridades: invertir en una zona de riesgo. Era imposible para el gobierno aceptar o promover la reconstrucción en lugar de tanto riesgo, según los expertos, pero no era menos importante cuánto se podía invertir y para qué población.

Decimo primero: La fragmentación de la comunidad en grupos repartidos en muchas partes, no sólo propició a la larga el debilitamiento de la cohesión, las organizaciones locales y apego con Chaitén, aso- ciable al bajo nivel de retorno observable, ya que en la actualidad no habitan más de unas 1.500 personas o menos de 300 familias $^{6}$. Pero también esa dispersión, debe haber dificultado crecientemente la validez de diversas encuestas y dinámicas para estudiar las expectativas de estas personas respecto del proyecto Nueva Chaitén, y a la vez, es uno de los factores que dificultó el desarrollo de un discurso compartido para la solución que se adopta finalmente.

Pese a la gran inversión de fondos públicos para proteger a la población y facilitar su relocalización, con medidas asistidas por especialistas competentes, el discurso que sobrevive es más bien crítico del rol del Estado. Ugarte y Salgado (2014:157) señalan: Se percibe al Estado como el principal responsable del desastre, en la medida en que sus acciones tienen como consecuencia la dispersión territorial de las familias y comunidad en general, la prohibición de retornar al territorio y la incertidumbre constante respecto a su futuro, y agregan: [el Estado] es percibido, por sobre la presencia del volcán, como la principal amenaza en el territorio.

La ayuda del Estado y el tiempo, hicieron cada vez más viable y atractivo recomenzar la vida en los lugares de acogida. En cambio, frente a estas facilidades para adaptarse a nuevos entornos, las que también deben ser leídas como oportunidades, la ciudad de Chaitén se empezó a percibir de manera más intensa como precaria y su condición de habitable fue siempre "una completa incertidumbre" (González, 2011:119), ya que nunca estuvo claro si se podía volver a la misma, ni cuándo, así como tampoco hubo señales que verdaderamente se estuviera reconstruyendo en la Nueva Chaitén en Santa Bárbara. En muchos de nuestros registros de campo se repite la siguiente sentencia: todo se veía bello, pero todos sabíamos que no se podía construir en medio del mallín.

\section{ANÁLISIS}

La espera se prolongó por meses y años, y una sucesión de eventos sociales, naturales y políticos no sólo impidió que se construyera la ciudad proyectada, sino también que muchos no regresaran a la Patagonia. Lo ocurrido, conforme a los antecedentes, es un caso ilustrativo de los encuentros y desencuentros entre la política, la academia y la ciudadanía en el idílico escenario de exuberante naturaleza proporcionado por la entrada a la Patagonia occidental.

La descripción de los rasgos más relevantes de la ciudad que se proyectó y el análisis de los factores que abortaron su concreción constituyen una experiencia que se debe examinar tanto para el futuro de la zona afectada y también como oportunidad para hacer visible la compleja relación entre la ciencia y la política en las situaciones de catástrofes. En lo medular, sostenemos que hubo allí una oportunidad académica y política que se perdió para generar un modelo virtuoso de habitabilidad, ya que las decisiones que surgieron de diversas fuentes dejaron como saldo una Patagonia más despoblada y una larga lista de secuelas emocionales, sociales, económicas y políticas que son difíciles de cuantificar.

El centralismo ofrece un mínimo común denominador, pero no máximos comunes denominadores. Esto significa que, lo que se distribuye como bienes, servicios y derechos en este tipo de regiones y localidades es siempre inexistente o el mínimo. Solo desde el punto de vista institucional no hay gran descentralización de servicios y no se encuentra CORFO, SERCOTEC e INDAP. Por tanto, hay una limitación básica de toda autoridad local en el recoger las demandas locales y en ejercer relaciones virtuosas con autoridades y servicios. 
A partir de ello, apreciamos dos matrices sociopolíticas: la del Estado y la de la comunidad organizada. Lo importante, es la segunda, ya que se construye con una lógica distinta y por oposición al Estado. Aquí, como ocurre en la Patagonia, hay otras raíces socioculturales que el poder central desconoce y una larga lista de promesas incumplidas. Parte de la sociedad tomó sus decisiones con información fragmentada, articulando nociones y puntos de vista muy diferentes, porque el tiempo también corre de manera distinta. Las personas individual y colectivamente no son capaces de cuantificar el riesgo. En este caso, los rebeldes resultaron más fuertes que el rigor académico y los estudios técnicos como el de la PUC y recibido por el gobierno.

Lo ocurrido con lo que iba a ser la ciudad modelo y puerta de entrada de la Patagonia, es un ejemplo del cómo la política territorial la terminó definiendo por omisión la ciudadanía, o parte de ella. Sin duda, en los resultados debemos reconocer una lucha por la posesión y control del territorio fuertemente influenciada por "los rebeldes", que fue la forma de ejercicio del poder que constituyó el límite de posibilidad de un proyecto para relevar a Chaitén como un tipo ideal y el territorio patagónico.

Fueron algunos de los vecinos los que contradiciendo explícitamente a autoridades políticas y a expertos, es decir, sobrepasando al Estado (su presencia histórica, diremos), los que imponen como solución final la habitabilidad del pueblo y el retorno. Para algunos, el arraigo por razones emocionales, económicas, familiares e históricas fue más efectivo que todas las medidas y declaraciones emitidas por parte de las autoridades y expertos vulcanólogos. Esto solidifica una cuestión conceptual: cada territorio se forma en el espacio geográfico a partir de relaciones sociales. Y, en este caso, el largo litigio contra el Estado respecto del reconocimiento de lo difícil que es vivir en una zona aislada, precaria en lo institucional y en los servicios, sumado a la desconfianza de promesas incumplidas, se selló con la recuperación de Chaitén, no importando que no tenga forma y no sea como los "pueblos argentinos".

Si se piensa el caso con lógica territorial, Chaitén fue un espacio territorializado por una fuerza pionera, autónoma, marcada por relaciones de poder; racionalizado por un conjunto de actores sociales que se articulan políticamente y frente a lo político que representa la institucionalidad del Estado. Las acciones emprendidas por "rebeldes" que se traducen en "Chaitén en Chaitén", representa un ámbito organizado y que tiene proyección social en lo que será la distribución de los bienes sociales, ya que decidió una opción por un tipo de actividades y por una escala para la localidad.

Lo objetivo es que, a través de una oposición al cierre definitivo del poblado y la demora de las resoluciones de las autoridades políticas, se decidió sobre los asuntos de la vida social: tamaño, cuántos y con qué servicios. Así, Chaitén se hizo largamente espurio, con reuniones fatigosas, insondables y amargas letanías; se mitigaron las demandas, se resolvieron hostilidades y antagonismos, y la situación --más de seis años- es que el pueblo se encuentra dañado y minimizado en su densidad y tejido urbano. Menos de un cuarto de su población ha regresado o se interesó en el retorno. Entonces, las preguntas rondan: ¿Era necesario Chaitén para el Estado? ¿De qué magnitud? ¿Para qué y quiénes?

El caso Chaitén y su impacto en el territorio patagónico, retrotrae a la experiencia pionera y de la colonización como ocupación originaria. Es un espacio principalmente que contiene estas dos claves como cuestión basal. De modo que, habla de los límites de propiedad, apropiación, autonomía y una cierta juridicidad con la que se han resuelto las cuestiones en el pasado, por lo que el territorio está representado por la presencia de un orden compuesto por parte de la comunidad, pequeños empresarios y familias con recursos e influencias diferenciadas. Por ello, la clásica frase acuñada en la Patagonia, "ir a Chile”, representa no sólo la lejanía y el sentir de distancia, sino el fondo de una manera autónoma de resolver las cuestiones, prescindiendo de las urgencias, tiempos y escuchas de las autoridades regionales y nacionales. $Y$, en este caso, el territorio es un instrumento político institucionalmente manipulado en manos de alguien. En esta situación, las decisiones corrieron por cuenta de "los rebeldes".

En perspectiva, la reducción de la población a un tercio es un empobrecimiento del potencial de desarrollo y calidad de vida del hinterland rural y el sistema de pueblos y localidades con los cuales intercambian servicios. Es claro que, con menos población las autoridades locales tienen menos cuestiones que negociar con una institucionalidad superior.

El aislamiento que sufre Chaitén y muchas las localidades de la provincia de Palena, es también un costo para las generaciones actuales: Chaitén perdió vida, es un mercado más pequeño, hay menos ciudadanos que voten, opinen y protesten, menos niños en su escuela y en sus calles, menos mano de obra, menos público para realizar eventos, menos lectores, menos conversaciones. $Y$, el que la mayor parte de las familias hayan decidido no regresar cuando se les facilitó la opción de radicarse en las ciudades de refugio, dice algo respecto de lo dura que puede resultar la vida en zonas tan aisladas, detrás de esa frontera interior.

Quizás, las probabilidades de haber impedido el despoblamiento fueron muy pocas, en las condiciones que se dieron los acontecimientos, pero lejos, hubo una oportunidad para Chaitén y para la Patagonia que se perdió: la ciudad ecológica modelo, una oportunidad que estuvo tan cerca. "La Nueva Chaitén" era un proyecto único, con enormes proyecciones, un atractivo obligatorio para habitantes, turistas y viajeros, incluso o estímulo para regresar. Pero, ello dice también de cuál es el papel del Estado y cuánto el Estado quiere ser en estos territorios interiores y de frontera. Ya con mucha desconfianza acumulada, con décadas de promesas incumplidas, de abandono, de falta de servicios y de protección social, fue más fácil que otros llegados desde cualquier parte, encontraran un lugar para vivir en territorios baldíos junto con los "rebeldes", para constituir una periferia social interior en Chaitén.

Si en la Patagonia la demografía es frágil, con un crecimiento reducido que se concentra en dos o tres escenarios urbanos (Puerto Montt, Coyhaique y Punta Arenas), mientras el aislamiento crítico es un rasgo de la mayor parte de su territorio, son justamente las comunas más aisladas las que más sufren ese despoblamiento. La catástrofe urbana y demográfica de Chaitén, no deja de ser un menoscabo a la habitabilidad de la provincia y de todo el territorio. Es un fortalecimiento a la condición de frontera interior y a la configuración de un archipiélago de poblados y familias dispersas con escasa ayuda, de zona apartada de Chile y de falta de visión en términos de ordenamiento territorial del Estado de Chile.

El aislamiento y la distancia significan un costo de vida más alto, menos oportunidades, menor esperanza de vida. En Palena, es 10 años menos que en el resto del país (El Mercurio, 31 marzo 2013, 13c). De todas formas la supervivencia es un poco más difícil, las oportunidades un tanto menos equitativas, para quienes nacerán 
en este territorio después de la catástrofe de Chaitén, aunque no podamos cuantificarlo. Pero, también debemos destacar que la vinculación entre ciencia y política, entre academia y sociedad fue deficiente: las esferas de los expertos, los políticos y la comunidad no se sincronizaron, no crearon puentes o narraciones compartidas que hubiesen generado provecho de las oportunidades que claramente hubo.

\section{CONCLUSIONES}

A. Como hemos revisado a lo largo de este escrito, tras la erupción del volcán Chaitén existen dos catástrofes: la de la ciudad, que corresponde a la destrucción de los volúmenes de la arquitectura; y, la social, que tiene que ver con la desarticulación de la red de sociabilidad. Esto último es lo más difícil de recomponer, o lo imposible, ya que hombres y mujeres iniciaron su éxodo con un muy pobre criterio sobre su dirección, pero con un futuro más incierto. Lo que se vive en más de una decena de lugares es el recuerdo de una madrugada infausta y la dispersión de la familia, la pérdida del sostén comunitario y la ritualidad cotidiana. Esto, no es un problema técnico sino humano, y constituye la deuda mayor de este proceso y también el error del mismo, porque las vidas comenzaron a disolverse y perderse dentro de un mundo mayor. Los hombres y mujeres se llevaron sus recuerdos lo más lejos posible sobre quienes habían sido en otro tiempo.

B. Con la ciudad informal que se reconfiguró luego del fallido plan Nueva Chaitén, se demuestra que la falta de decisión de las autoridades y quienes presionaron para que Chaitén se reconstituyera en Chaitén, ambos actores se ponen de espaldas a la naturaleza. Es decir, confirma lo señalado en las primeras líneas de este escrito, de que en el Tercer Mundo es frecuente que cuando el fenómeno decanta o se estabiliza en su urgencia, las condiciones de riesgo y vulnerabilidad son olvidadas nuevamente, porque no hay criterio de seguridad asumido como política. En este sentido, se mantiene la disposición a sufrir daño debido a posibles acciones externas.

C. Claramente las informaciones sobre el territorio fueron múltiples y diversas. No todos contaron con las mismas posibilidades en términos de acceso a ellas, las relaciones fueron diferenciadas, los tiempos de espera desiguales y muy disímiles las capacidades para intervenir substancialmente en la configuración de un cierto futuro en Chaitén o en el proyecto de una nueva ciudad. Quiénes tuvieron posiciones más ventajosas desde el punto de vista económico (tierras y servicios turísticos) se reinstalaron en Chaitén. Otros, reempezaron sus vidas en diferentes lugares y muy probablemente nunca volverán, especialmente cuando no se aprecia la inducción de ningún sistema virtuoso al cabo de seis años.

D. La sumatoria de los elementos detallados, nos muestra que en la configuración del territorio intervienen múltiples factores: relaciones sociales, económicas y políticas. De este modo, Chaitén, la puerta de entrada a la Patagonia, reflejó el cruzamiento de intereses y los límites de información y autonomía de cada proyecto. El centralismo del Estado pasó de la "suma urgencia" (lo antes posible) a "otras prioridades" (27F); y, con ello, nuevamente los tiempos políticos, académicos y comunitarios entraron en contradicción y se esfumaron sin lograr sincronía ni convergencia. El vacío u olvido en el que cayó el proyecto de la Nueva Chaitén, no sólo impacta sobre Chaitén o lo que queda de ésta, sino en una relación con el territorio provincial, regional y nacional, como parte de una política de ordenamiento y gestión territorial.

\section{REFERENCIAS}

AGUILERA, R. (2009) Chaitén El Lado B de la tragedia. Revista Nos. Febrero 2009. Recuperado 10 enero 2010: http:// www.revistanos.cl/2009/02/chaiten-el-lado-b-de-latragedia

ALFARO, V., CHAHUÁN, C. y REYES, C. (2010) Chaitén, la comunidad fantasma de la carretera Austral. Pontificia Universidad Católica de Chile. Facultad de Ciencias Sociales. Escuela de Trabajo Social. Desarrollo Comunitario y Ciudadanía.

ANGENOT, M. (2010) El discurso social. Los límites históricos de lo pensable y lo decible. Buenos Aires: Siglo XXI Editores.

AUGÉ, M. (1993) Los no lugares espacios del anonimato. Una antropología de la sobremodernidad. Barcelona: Gedisa Editorial.

BURGOS, J. P. (2009) “Bernardo Riquelme, locutor de Chaitén: ‘Lo que menos hacemos es andar preocupados del volcán'”. Diario El Ciudadano, 27 febrero 2009, página 23.

CARN, S. A., et al. (2009) The Unexpected Awakening of Chaitén Volcano, Chile, Vol. 90, N 24:16.

COOPERATIVA (9 abril 2011) Piñera dio a conocer "Plan Solución Chaitén" y oficializó refundación de la ciudad. Recuperado 7 noviembre 2012: http://www.cooperartiva.cl/npticias/ pais/region-de-los-lagos/volcan-chaiten/pinera-dio-aconocer-plan-solucion-chaiten-y-oficializo-refundacion-dela-ciudad/2011-04-09/223055.html

DIVISIÓN DE DESARROLLO URBANO-MINVU (2010) Plan Maestro Ciudad Chaitén. Informe final, marzo. Ministerio de Vivienda y Urbanismo. Recuperado 5 octubre 2012, http://www.plataformaurbana.cl/wp-content/uploads/201/04/1270556064_plan_chaiten_informe_final.pdf

DREF (14 may 2008) Chile: Volcanic Eruption DREF Operation $N^{\circ}$ MDRCL003. International Federation of Red Cross and Red Crescent Societies. Recuperado 15 enero 2013: http:// www.redhum.org/archivos/pdf/ID_2232_Redhum_CL_ DREF_Operation_No._MDERCL003_Volcanic_Eruption.pdf

DE LA BARRERA, F., REYES-PAECKE, S. y MEZA, L. (2011) Análisis del paisaje para la evaluación ecológica rápida de alternativas de relocalización de una ciudad devastada. Revista Chilena de Historia Natural 84:181-194.

EL MERCURIO (31 de marzo de 2013) Esperanza de vida es 10 años menor en las comunas de las Guaitecas, Palena y Camiña, página 13c.

(2 junio 2010).

FANTINI, F. (2007) Patagonia Chilena. Historia. Santiago: Edit. Patagonia Media.

FETTERMAN, D. (2010) Ethnography. CA, USA: SAGE Publications.

GONZÁLEZ, R. (2011) Estudio del impacto territorial-ambiental generado por la erupción del volcán Chaitén. Memoria para optar al Título de Geógrafa, Escuela de Geografía, FAU, Universidad de Chile. 
LA NACIÓN (27 mayo 2010) Piñera Confirma Reubicación de Chaitén en Santa Bárbara. Recuperado el 12 de noviembre de 2012, http://www.lanacion.cl/pineraconfirma-reubicacion-de-chaiten-en-santa-barbara/noticias/2010-05-27/180052.html

LARA, L. (2009) The 2008 Eruption of Chaitén Volcano, Chile: A Preliminary Report. Geological Note. Andean Geology 36 (1):125-129. January, 2009.

MACAYA, P. (2012) Volcán Chaitén: Consecuencias y discusiones. Ensayo en teoría y política ambiental. Universidad de Heidelberg-UCH-PUC, Santiago.

MARCHANT, J. (2010) Lágrimas de ceniza. Estudio cualitativo sobre la experiencia de desplazamiento de los habitantes de Chaitén, asentados en las ciudades de la Isla de Chiloé y Puerto Montt. Universidad de Chile, Proyecto de Práctica Profesional. ONEMI, División de Protección Civil.

(2011): Desplazamiento de Chaitén desde una perspectiva psicosocial. ¿Qué ocurrió con su población después del desastre? Leipzig: Editorial Académica Española.

NASA, Earth Observatory: Chaiten Volcano Erupts, may 2008. Recuperado 5 noviembre de 2012, http://earthobservatory. nasa.gov/NaturalHazards/view.php?id=19887

PUC-OBSERVATORIO DE CIUDADES (2009) Consultoría para el desarrollo de lineamientos estratégicos de reconstrucción/ relocalización y Plan Maestro Conceptual Post-Desastre Chaitén. Informe Final Etapa 1, Noviembre 2008 (Versión abril 2009). Recuperado 4 octubre de 2012, http://www. goreloslagos.co/resources/descargas/acerca_de_gore/ doc_gestio/chaiten/1er_informe_version_final.pdf. Informe Final Etapa 2, Diciembre 2008 (Versión abril 2009). Recuperado 4 octubre de 2012, http://www.goreloslagos. co/resources/descargas/acerca_de_gore/doc_gestio/ chaiten/2do_informe_version_final.pdf. Informe Final Etapa 3, (junio 2009). Recuperado 4 octubre de 2012, http:// www.goreloslagos.co/resources/descargas/acerca_de_ gore/doc_gestio/chaiten/3er_informe_version_final.pdf

OXFORD DICTIONARY (2014). Oxford University Press.

REYES, S., RODRÍGUEZ, J. C. y MEDINA, P. (2014) “El sufrimiento colectivo de una ciudad minera en declinación: el caso de Lota, Chile. Horizontes Antropológicos, Ano 20, N 42, jul/ diz:237-264, Porto Alegre.

RODRÍGUEZ, J. C., MEDINA, P., REYES, S. (2014) Territorio, paisaje y marketing global: Imaginarios en la construcción de la Patagonia como marca. Magallania, Vol. 42, № 2:109124, Punta Arenas.

SERNAGEOMIN (2008) Los flujos de lodo que afectan a Chaitén continúan extendiéndose. La Tercera 13 de mayo. Recuperado 3 febrero de 2013, http://www.latercera.com/contenido/25_12135_9.shtml

SUBDERE-PUC (1999) Diagnóstico y propuestas para la integración de territorios aislados. Santiago: LOM Ediciones.

STAKE, R. (1978) The Case Study Method in Social Inquiry. Educational Researcher, Vol. 7, N²:5-8.
UGARTE, A. y SALGADO, M. (2014) Sujetos en emergencia: acciones colectivas de resistencia y enfrentamiento del riesgo ante desastres; el caso de Chaitén, Chile. Revista INVI, N ${ }^{\circ}$ 80, mayo 2014, Vol. N²9:143-168.

WILCHES-CHAUX, G. (1993) La vulnerabilidad global. En: Los Desastres No Son Naturales. Compilador: Andrew Maskrey, Red de Estudios Sociales en Prevención de Desastres en América Latina.

YIN, R. (2013) Case Study Research. Design and Methods. USA: SAGE Publications.

\section{NOTAS}

1 Este artículo es resultado del proyecto FONDECYT 1120795 Etnografía de la colonización y recolonización de Chiloé Continental. Actores, intercambios y conflictos.

2 No resulta extraña la aseveración, ya que como hemos expuesto en otro trabajo, en la Patagonia las relaciones no son longitudinales sino horizontales, observándose parejas de ciudades y localidades binacionales en toda la Patagonia, y la Provincia de Palena no es la excepción (Rodríguez et al. 2014).

3 Este beneficio para los damnificados sólo será superado el año 2010 en el caso de los 33 mineros atrapados en la mina San Lorenzo en las cercanías de Copiapó.

4 VHP-USGS, Volcano Hazard Program of United States Geological Survey.

5 Registro de campo, octubre de 2012.

6 Datos proporcionados por el Departamento de Desarrollo Comunitario de la Municipalidad de Chaitén.

68 > Revista Márgenes No 15 Vol 11 > Diciembre 2014: 57 a 68 Facultad de Arquitectura > Universidad de Valparaíso 